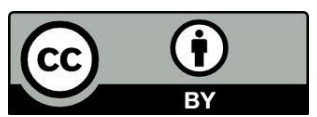

\title{
NOTAS HISTÓRICAS E ANTROPOLÓGICAS SOBRE O BATUQUE NO RIO GRANDE DO SUL
}

The gaucho Batuque: Notes on the history of african-Brazilian religions in southern Brazil

\author{
Marcelo Tadvald \\ Doutor em Antropologia - UFRGS \\ Núcleo de Estudos da Religião - NER -UFRGS \\ e-mail: marcelotadvald@gmail.com
}

RESUMO: Devido a fatores históricos e sociais particulares, encontramos poucos dados disponíveis a respeito das religiões de matriz africana que se constituíram em diferentes partes do país desde o começo do período colonial. Com importantes variações conforme a região, seguramente esta se trata de uma realidade para o Batuque gaúcho, este que consiste na modalidade afrorreligiosa que surgiu e se desenvolveu no extremo sul do Brasil, e que tem em Porto Alegre uma importante referência, constituindo esta cidade no centro de circulação desta religião para o mundo. A partir de fontes diversas, como relatos coletados em vivências etnográficas, informações disponíveis em sítios virtuais e em dados oficiais, este trabalho busca analisar aspectos particulares a respeito das dinâmicas de estabelecimento territorial e simbólico e de trânsito e estabelecimento dessas comunidades religiosas desde o sul brasileiro e para além dele.

Palavras chave: Religiões afro-brasileiras; Batuque gaúcho; territorialização.

ABSTRACT: Due to historical and social factors in particular, we found few data available about the religions of African origin that were formed in different parts of the country since the beginning of the colonial period. With significant variations by region, surely this is a reality for the gaucho Batuque, was consisting in afrorreligiosa modality that has emerged and developed in southern Brazil, which has in Porto Alegre an important reference, making this city the center of movement of this religion to the world. From various sources, as collected reports on ethnographic experiences, information available in virtual sites and official data, this paper seeks to analyze particular aspects about the dynamics of territorial and symbolic establishment and transit and establishment of these religious communities from southern Brazil and beyond.

Keywords: African-Brazilian religions; the gaucho Batuque; territorialization. 


\section{Introdução - Alupô $!^{1}$}

Dispõe-se de escassos dados históricos ou estatísticos a respeito das religiões de matriz africana que se constituíram em diferentes partes do país desde o período colonial. Muitas vezes tal escassez de dados ou de fontes confiáveis repercute no baixo índice de trabalhos sobre determinados assuntos, prejudicando o seu entendimento mais aclarado. Ademais, o desinteresse da "historiografia oficial" de tempos passados no registro de temas e de populações desconsideradas enquanto protagonistas dos cursos da sua própria história e da sociedade em geral, são aspectos que contribuem para a invisibilização dessa realidade. Este parece ser o caso aqui, quando voltamos a nossa atenção ao Batuque, um exemplo do vasto conjunto afrorreligioso brasileiro, culto considerado genuinamente gaúcho e que tem em Porto Alegre a sua maior referência, constituindo esta cidade na "capital difusora" desta modalidade religiosa para o mundo.

A partir de fontes diversas, como relatos coletados em campo e dados disponíveis em sítios virtuais, êmicos ou institucionais, como o Primeiro censo das casas de religiões afrobrasileiras de Porto Alegre elaborado pelo Centro de Pesquisa Histórica (CPH) da Prefeitura da cidade entre 2006-2008, este texto busca analisar aspectos particulares, especialmente históricos, territoriais e etnográficos a respeito das dinâmicas de circulação e de distribuição dessas comunidades de terreiro no espaço porto-alegrense urbano e simbólico.

Assim, o texto está dividido em duas partes principais: primeiramente, ofereço um breve histórico a respeito das religiões de matriz africana no Brasil em geral e no Rio Grande do Sul em particular, para assim apresentar alguns dados também históricos sobre a presença das populações de origem africana na capital rio-grandense, ao contrário das imagens e mitos deveras difundidos que constantemente invisibilizam o componente afro-orientado constituinte da identidade gaúcha. A seguir, discorro sobre a formação e a consolidação do Batuque, apresentando por fim algumas considerações gerais a respeito de suas idiossincrasias.

\section{Notas sobre as religiões de matriz africana no Brasil e no Rio Grande do Sul}

As religiões afro-brasileiras são o resultado de um longo processo envolvendo a

\footnotetext{
${ }^{1}$ Saudação do Batuque ao orixá Bará, que significa: abra as portas do caminho ou que venha o falante.
} 
conservação e a transformação da memória coletiva africana no Brasil. Num contexto marcado pela realidade escravocrata, populações negras traficadas como mão de obra trouxeram consigo culturas próprias por sua vez ressignificadas e rearticuladas de acordo com as demandas desta nova realidade social e geográfica imposta.

Em termos linguísticos, registra-se atualmente em África cerca de duas mil línguas faladas, o que corresponde em torno de um terço das línguas vivas do mundo. Esta diversidade linguística pode ser dividida em dois grandes troncos: o bantu e o sudanês $(\mathrm{kwa})$. Estes troncos possuem subdivisões importantes. O bantu, que consiste em aproximadamente dois terços das línguas faladas na África subsaariana (da África do Sul à República Centro Africana, passando por vinte países), divide-se em várias línguas, tais como: quicongo (a língua nacional em Congo Brazzaville, República Democrática do Congo, Congo Kinshasa (ex-Zaire) e Angola, também falado pelos bacongo e outros grupos regionais), o quimbundo (falado pelos ambundo, em Angola e Luanda), o umbundo (falado pelos ovimbundo, no sul de Angola), assim como outras línguas isoladas como o duala (língua/ povo presente na República dos Camarões e Guiné Equatorial), além angolas, caçanjes, benguelas, cabindas, entre outros.

O sudanês $(k w a)$, por sua vez, está situado mais propriamente na África Ocidental, em países como: Senegal, Nigéria, Benin (ex-Daomé), Togo, Serra Leoa, Gana, Gâmbia, entre outros. As principais línguas sudanesas são o ioruba ou nagô, subdivididas em vários falares, como oiós, keto (nagô é uma língua ioruba falada no reino de Keto), ijexa, egba, ifés. Estas línguas comumente cultuam certas divindades (orixás) no Brasil. Outras línguas importantes do tronco kwa são o jeje (ewe ou fon, mina, gun e mahi, estes que cultuam voduns) e o akam (fanti-ashanti). Também compartilham do tronco sudanês grupos islamizados, como os haussa, tapa, peul, fula e mandinga. No Brasil, estes grupos chegaram e se concentraram, sobretudo na Bahia e em Pernambuco entre séculos XVII e XIX.

Assim, aproximadamente dois terços dos escravizados trazidos para o Brasil eram bantos, aqui conhecidos como congos, angolas ou cabindas, tendo se espalhado por quase todo o litoral e centro-oeste do país, nas regiões que hoje abrigam os Estados de Minas Gerais e Goiás. Tiveram influência notória na construção da cultura brasileira, sobretudo na culinária, música e língua, além de aspectos religiosos percebidos desde o período colonial a partir dos autopopulares, denominados de congas e congadas, ou 
também moçambiques, além do culto aos antepassados e à ancestralidade que marcam até hoje esta matriz cultural e religiosa nacional.

Portanto, para o Brasil foram trazidos africanos de mais de uma centena de povos diferentes e sua herança cultural foi inevitavelmente sincretizada ou conjugou ecletismos com outras formas de religiosidade, especialmente com o catolicismo, com a espiritualidade indígena e, posteriormente, com o espiritismo kardecista, dando origem a manifestações religiosas brasileiras inteiramente novas e que, no curso das últimas décadas, tem se transnacionalizado para outros países (Bem, 2012).

No que se refere ao campo afrorreligioso mais propriamente, de acordo com Ari Pedro Oro (2005), a expressão "religiões afro-brasileiras" cobre uma variedade de cultos organizados no Brasil e que podem ser condensados, segundo um modelo idealtípico, em três diferentes expressões ritualísticas. A primeira delas cultua os orixás africanos (nagô) e privilegia os elementos mitológicos, simbólicos, linguísticos, doutrinários e ritualísticos das tradições banto e nagô. Neste grupo se encontram o Candomblé da Bahia, o Xangô de Recife, o Babaçuê no Pará, o Batuque do Rio Grande do Sul e a Casa de mina do Maranhão, modalidades regionais como são conhecidos alguns dos cultos de matriz africana pelo Brasil e que possuem variações litúrgicas e estruturais importantes entre si devido às suas diferentes origens linguísticas e culturais e ao seu encontro e reorganização promovidas em solo brasileiro.

A segunda forma ritual, que parece ter surgido no Rio de Janeiro no final do século XIX, inicialmente chamada de Macumba, recebeu mais tarde nomes diferentes de acordo com as regiões brasileiras, os mais comuns sendo Quimbanda, Linha negra, Umbanda cruzada e Linha cruzada. Essa expressão religiosa afro-brasileira cultua os exus e as pombagiras, entidades de intermediação entre os homens e os orixás. Tais expressões realizam imolações de animais. A terceira forma ritual é a Umbanda, também chamada em alguns locais de Umbanda linha branca, surgida no Rio de Janeiro, no começo do século XX, estruturada de forma sincrética a partir de elementos provenientes das tradições católica, africana, indígena, kardecista, oriental, centrando-se no culto aos pretos-velhos (muitos deles tidos por entidades que foram pessoas escravizadas em outra vida) e caboclos (entidades indígenas comumente relacionadas às questões de saúde e de curandeirismo). Esta modalidade não realiza a prática do sacrifício de animais. Também é chamada de Linha cruzada a conjunção entre essas 
vertentes religiosas, dentro de um sistema interdependente. No caso de algumas religiões, como o Batuque gaúcho, por exemplo, muitas casas desta linha cruzada também cultuam pretos-velhos e caboclos, realizando assim rituais e práticas umbandistas de linha branca, havendo inclusive tal reconhecimento.

Dito de outro modo, o Batuque representa a expressão mais africana do complexo afrorreligioso gaúcho, pois a linguagem litúrgica é iorubana, os símbolos utilizados são os da tradição africana, as entidades veneradas são os orixás e há uma identificação às "nações" africanas. A umbanda representa o lado mais "brasileiro" do complexo afrorreligioso, pois se trata de uma religião nascida por aqui a partir do sincretismo de suas principais ontologias religiosas: a cristã e a africana. Seus rituais são celebrados em língua portuguesa/ brasileira e as entidades veneradas são, sobretudo, os "caboclos" (índios), "pretos-velhos" e "cosminhos" (crianças), além das "falanges africanas" (Corrêa, 1994).

No mais, todas elas são religiões de possessão ou mediúnicas, segundo algumas definições possíveis, quer dizer, as entidades espirituais se apoderam dos médiuns/ filhos-de-santo mediante o estado de transe. São também religiões de iniciação, isto é, o ingresso na religião ocorre a partir de uma série de rituais que visam aprofundar a integração do sujeito a ela; religiões mágicas, no sentido de atender às demandas específicas dos sujeitos, sobretudo nas áreas da saúde, econômica e sentimental; religiões emocionais, que envolvem o indivíduo como um todo, o corpo ocupando um lugar de destaque; religiões universais, pois estão abertas aos indivíduos das distintas camadas sociais e de diferentes grupos étnicos ou de orientação cultural, política e sexual; e religiões transnacionais, ou seja, interagem com indivíduos de outros países, sobretudo aqueles que fazem fronteira com o Rio Grande do Sul: argentinos e uruguaios (Frigerio, 1989; Pi Hugarte, 1997; Oro, 1999; De Bem, 2012; Tadvald, 2014).

As diferentes formas de estruturação das religiões de matriz africana no Brasil acompanham, portanto uma lógica complexa, que muitas vezes reúne sincretismos e significações a partir de diferentes referenciais religiosos, linguísticos e culturais. Desta forma não é incomum a possibilidade de inclusão de outras práticas do campo mediúnico ou para além deste, até mesmo de forma autônoma conforme cada casa de santo e terreiro/a, ou de certos sincretismos ou ressignificações desses elementos com referentes religiosos orientalistas ou mesmo camponeses e sertanejos. 
Atualmente, as religiões de matriz africana são professadas livremente perante a lei, ainda que certos grupos busquem ressignificar de formas múltiplas as históricas perseguições a este campo no intuito de modificar a norma legal no sentido de promover um retrocesso jurídico e social, como é o caso de certos projetos de lei que visam a proibição das imolações de animais em diferentes cidades brasileiras (Tadvald, 2007). Assim, a formação das afrorreligiões no Brasil se dá num contexto, desde o período colonial, em que o catolicismo já se assumia enquanto religião oficial do país, e em que todo o brasileiro, obrigatoriamente, deveria ser batizado, assumindo assim a fé católica.

Todavia, o Brasil é um país com relativa diversidade religiosa. A maior parte da população se declara católica, mas diversas religiões são praticadas no país, segundo os dados apresentados a seguir.

\section{Quadro 1 - Religiões no Brasil (Censos de 1980-2010)}

\begin{tabular}{c|cccc} 
Religião & $\begin{array}{c}\text { Censo } \\
\mathbf{1 9 8 0}\end{array}$ & $\begin{array}{c}\text { Censo } \\
\mathbf{1 9 9 1}\end{array}$ & $\begin{array}{c}\text { Censo } \\
\mathbf{2 0 0 0}\end{array}$ & $\begin{array}{c}\text { Censo } \\
\mathbf{2 0 1 0}\end{array}$ \\
\hline $\begin{array}{c}\text { Catolicismo } \\
\text { Romano }\end{array}$ & $89,2 \%$ & $83,3 \%$ & $73,7 \%$ & $64,6 \%$ \\
Protestantismo & & & & \\
Espiritismo Kardecista & $0,6 \%$ & $9 \%$ & $15,4 \%$ & $22,2 \%$ \\
Afrorreligiões & $0,7 \%$ & $1,1 \%$ & $1,4 \%$ & $2 \%$ \\
Outras religiões & $1,3 \%$ & $0,4 \%$ & $0,3 \%$ & $0,3 \%$ \\
Sem religião & $1,6 \%$ & $1,4 \%$ & $1,9 \%$ & $2,9 \%$ \\
\hline Total & $100 \%$ & $7,8 \%$ & $8 \%$ \\
\hline Fontes: Pierucci (2004) e Censo 2010 (www.ibge.gov.br). & & & \\
\hline
\end{tabular}

Atualmente, conforme os dados do censo demográfico de 2010 apresentados no quadro acima, é possível verificar que, ao somarmos as três principais religiões de matriz cristã, chegamos ao patamar de $88,8 \%$ da população nacional (pouco mais de 169 milhões de pessoas). Considerando os $8 \%$ que se declaram sem religião, restam apenas $3,2 \%$ da população brasileira que se declara pertencente a outras religiões não necessariamente de matriz cristã, isto desconsiderando, por exemplo, a Umbanda ou outras religiosidades sincretizadas com o cristianismo, que poderiam diminuir ainda mais este percentual. Assim, estes módicos 3,2\% representam, conforme a catalogação do IBGE, $0,7 \%$ (1,4 milhão) de pessoas que se declaram testemunhas de Jeová; $0,5 \%$ 
(um milhão) declaram-se os santos dos Últimos Dias ou mórmons; 0,3\% (588 mil) declaram-se seguidores do animismo afro-brasileiro como o Candomblé, o Tambor-demina, além da Umbanda; 1,6\% (3,1 milhões) declaram-se seguidores de outras religiões, tais como: islâmicos (300 mil), budistas (243 mil), judeus (196 mil), messiânicos (103 mil), esotéricos (74 mil), espiritualistas (62 mil) e os ayahuasqueiros (35 mil). Há ainda registros de pessoas que se declaram baha'ís e wiccanos, porém nunca foi revelado um número exato dos seguidores de tais religiões no Brasil (IBGE, 2014).

A partir do que indica os números do Quadro 1, é possível entender - não somente certas religiões de matriz africana assim como todas as demais que eventualmente não se utilizam do expediente cristão em sua fundamentação - enquanto religiões de resistência e de afirmação cultural no Brasil. Não por acaso, segundo veremos adiante, esta se trata de uma representação comum aos povos de terreiro do Batuque gaúcho, sendo constituinte inclusive de um de seus mitos de origem.

No Rio Grande do Sul também chama a atenção o fato deste Estado ser, desde o Censo de 2000, como o "mais afrorreligioso do país" no sentido da autoatribuição religiosa, seguido por Rio de Janeiro, Bahia e São Paulo, todos com percentuais acima do índice nacional. Por hora não haverá como avançarmos neste aspecto, mas há muitos anos registram-se, no Estado sulista, campanhas afirmativas em prol desta visibilidade e reconhecimento (como a mais recente delas promovida por diversos coletivos sociais: “Quem é de Axé diz que é”!), em parte fruto de um Estado que construiu a sua identidade no sentido de excluir o componente negro de sua representação (Oliven, 2006; De Bem, 2012).

Fato é que entre as décadas de 1990 e 2000 houve, no país, uma diminuição de indivíduos que afirmaram sua identidade religiosa associada às religiões afro-brasileiras, ao passo em que se registrou no Rio Grande do Sul um aumento de mais de $33 \%$ no mesmo período. De fato, são 157.599 indivíduos deste Estado, o que corresponde a $1,47 \%$ da população total, que reivindicaram o seu pertencimento religioso afrobrasileiro. Esta porcentagem sobe para $2,52 \%$ se tomarmos como referência a região metropolitana de Porto Alegre e para 3,35\% se nos restringirmos somente a Porto Alegre. Ainda segundo o Censo 2010, a porcentagem de pertencimentos afrorreligiosos no Rio de Janeiro baixou para 0,89 e na Bahia subiu para 0,34\%, igualando a São Paulo, constituindo-se, Bahia e São Paulo como sendo, atualmente, o segundo e o terceiro 
Estados com maior representatividade afrorreligiosa. Os demais Estados em que se reconhece a existência dessas religiões apresentaram os seguintes índices: Pernambuco 0,14\%, Pará 0,07\% e Maranhão, 0,06\%.

Assim, estudiosos e líderes religiosos estimam em cerca de 30.000 terreiros espalhados em todo o Estado, com maior concentração na região metropolitana de Porto Alegre (Corrêa, 2006). Segundo o já referido Censo das Casas de Religião Afro de Porto Alegre (2006-2008), foram indexados cerca de 1.290 terreiros na capital, número muito semelhante ao registrado em Salvador da Bahia, posto que um recenseamento, realizado nesta cidade, em 2007, identificou 1.296 terreiros. Todavia, estima-se que tal registro de terreiros em Porto Alegre e região metropolitana estejam subestimados, pois que em realidade este número deve passar dos três mil.

Portanto esses índices, tanto os relativos ao Rio Grande do Sul quanto ao Brasil, não podem ser tomados como verdades absolutas, estimando-se que, na melhor das hipóteses, representarem metade daquilo que realmente existe em termos do número de terreiros afrorreligiosos no país.

\section{Surgimento e consolidação do Batuque}

Quanto ao mito fundador do Batuque, há duas versões correntes: uma que afirma ter sido ele trazido para o Rio Grande do Sul por uma escravizada vinda de Pernambuco; e outra que não o associa a uma personagem, mas às etnias africanas que o estruturaram enquanto espaço de resistência cultural e simbólica à escravidão.

Assim, a teoria mais provável explica que o Batuque consiste em uma religião originada no Rio Grande do Sul entre 1833 e 1860 (Lírio de Mello, 1995; Corrêa, 2006) a partir das religiões praticadas por escravizados de origem banto e sudanesa provenientes de Pernambuco e que se estabeleceram primeiramente nas cidades portuárias de Rio Grande e de Pelotas (Oro, 2002). A maioria dos escravizados que aportaram na região, desde os períodos anteriores, era de origem banto, constituindo-se como o grupo predominante nesta onda de colonização forçada ao Estado. Sua predominância pode ser verificada, por exemplo, a partir da quantidade de expressões de sua língua, o quimbundo (ou kibundo), incorporadas ao português corrente (por exemplo, “quitanda”, “tanga”, “farofa”, “fubá”, “jiló”, “minhoca”, “canjica”, “bunda”, 
"cochilo", "gingar", "samba", "batuque", "umbanda", "quimbanda" entre muitas outras). Contudo, mesmo que em menor escala do que a de bantos e apesar da predominância cultural exercida por este grupo neste período, credita-se à migração de comunidades sudanesas a formação e a cosmologia dos primeiros terreiros de Batuque (Acosta, 1996; Corrêa, 2006).

Também a origem do Batuque pode ter tido um ancestral comum ao culto originado no nordeste brasileiro conhecido como Xangô do Recife, ancestral, portanto já estabelecido no Brasil e não em África. Embora os orixás da cosmologia do Batuque sejam praticamente os mesmos venerados no Candomblé baiano de origem ketu, também da etnia ioruba, a maneira de "cultuá-los" e de "assentá-los" (praticar o "fundamento religioso") é considerada muito semelhante ao modo litúrgico do Xangô do Recife (como, por exemplo, no caso do estilo jeje de tocar os tambores [Carvalho, 1987]), e consideravelmente diferente em aspectos fundamentais daquilo que é realizado pelo culto baiano. De qualquer forma, o Batuque se constituiria a partir de diferentes grupos étnicos africanos que coabitavam nas concentrações urbanas mais importantes do período (Corrêa, 2006).

A partir de 1860, Porto Alegre começou a registrar maiores índices de crescimento do que cidades como Pelotas e Rio Grande, aumentando assim a sua demanda por trabalhadores. Ainda que se encontrem referências a respeito da lendária Casa de Mãe Rita, supostamente a primeira casa de religião africana na cidade, e de casas de "moças negras cantadeiras, aonde aos domingos iam moços passear para se reunir em cantos e danças", conforme descrevia o cotidiano da cidade à época o historiador e professor Coruja (Franco, 1988; 1991), 1860 é considerado o ano de fundação dos primeiros terreiros de Batuque em Porto Alegre, cidade que ao longo dos tempos se tornaria o maior centro de circulação desta religião.

A diversidade étnica africana presente na região e as trocas culturais aqui praticadas entre esses grupos estabeleceram o predomínio étnico e linguístico banto e a supremacia religiosa sudanesa, que marcou como jeje-nagô (ewé-yorubá) a organização inicial do modelo religioso do Batuque, caracterizado pela sólida estrutura e articulação litúrgica e pela disciplinada formação de seus sacerdotes. Contudo, para além do predomínio cultural banto e da presença sudanesa, a diversidade de populações de origem africana aglutinadas sob o Batuque proporcionou a sua divisão em diferentes 
"modalidades de culto", ou "lados", ou "nações", conforme a atribuição do batuqueiro a uma mesma tradição religiosa identificada como aquela praticada por dada ancestralidade étnica. As "nações" ou "lados" foram assim caracterizados de maneira a se distinguir da ideia de "religião", noção por sua vez englobante do Batuque e de outros cultos afrobrasileiros como a Umbanda ou a Quimbanda.

De acordo com os registros etnográficos disponíveis e coletados, não há concordância absoluta a respeito dos "lados" do Batuque. Todavia, as seis nações do Batuque comumente mais consideradas são: cabinda, oyó, ijexá, nagô, jeje e jeje-ijexá. Estas se diferenciam a partir de aspectos cosmológicos e técnicos, litúrgicos e musicais particulares, como o toque (ritmo) do tambor, uso ou não de alguns axés cantados ("pontos" ou rezas em língua ioruba ou banto), números ou ordens distintas na sucessão dos orixás, entre outros (Acosta, 1996). Contudo, como não é incomum que os terreiros atribuam pertencimento a duas ou mais nações, sendo que alguns aspectos que seriam originalmente diferenciadores entre os "lados" acabam se combinando na configuração e no "fundamento" de muitos terreiros.

Assim, o Batuque se divide em "nações" ou "lados", tendo sido, historicamente, os mais importantes: oyó, tida como a mais antiga do Estado, mas tendo hoje aqui poucos representantes e divulgadores; jeje, cujo maior divulgador "político e social" no Rio Grande do Sul foi o Príncipe Custódio, um príncipe africano que viveu neste Estado de 1889 a 1935, ano de sua morte, ainda que Dona Chininha e Joãozinho do Bará sejam os maiores responsáveis pela consolidação desta "Bacia" (Silva, 1999); ijexá, cabinda e nagô são outras nações de destaque, com predomínio, na atualidade, dos "lados" jejeijexá (Braga, 1998). Note-se que o ketu esteve historicamente ausente neste Estado, vindo somente nos últimos anos a ser integrado graças ao Candomblé. Independentemente das "nações", o Batuque do Rio Grande do Sul cultua fundamentalmente doze orixás, a saber: Bará, Ogum, Iansã (ou Oiá), Xangô, Oba, Odé/ Otim, Ossanha, Xapanã, Oxum, Iemanjá e Oxalá, ordem esta mais diretamente relacionada à nação cabinda. A cada um deles são atribuídas características específicas, símbolos, animais imolados e correspondências com santos católicos, resultantes dos mitos relatados nas duas tradições religiosas, conforme segue:

\section{Quadro 2}




\section{Orixás do Batuque do Rio Grande}

\begin{tabular}{|c|c|c|c|c|}
\hline Orixá & Atribuição & Símbolos & $\begin{array}{l}\text { Animais } \\
\text { sacrificiais }\end{array}$ & $\begin{array}{c}\text { Corresp. santos } \\
\text { católicos }\end{array}$ \\
\hline Bará & $\begin{array}{l}\text { Dono das encruzilhadas; } \\
\text { abridor dos caminhos; } \\
\text { Representa a força vital que } \\
\text { movimenta o universo. } \\
\text { Mensageiro dos orixás; orixá } \\
\text { da sensualidade. }\end{array}$ & $\begin{array}{l}\text { Chave, foice, moedas, } \\
\text { corrente, tridente. }\end{array}$ & bode, galo vermelho. & $\begin{array}{l}\text { S. Antônio, S.Pedro e S. } \\
\text { Benedito. }\end{array}$ \\
\hline Ogum & $\begin{array}{l}\text { Dono do trabalho em metal e } \\
\text { da agricultura, guerreiro } \\
\text { (demanda). }\end{array}$ & $\begin{array}{l}\text { Ferramentas em geral, } \\
\text { espada, faca, bigorna, } \\
\text { martelo, malho, lança, } \\
\text { lima. }\end{array}$ & Bode escuro, galo vermelho. & $\begin{array}{l}\text { São Jorge no Sul, Santo Antonio } \\
\text { na Bahia. }\end{array}$ \\
\hline Iansã & $\begin{array}{l}\text { Dona dos raios, ventos, } \\
\text { tempestades e das águas. }\end{array}$ & $\begin{array}{l}\text { Espada, taça, pulseira, } \\
\text { alianças. }\end{array}$ & $\begin{array}{l}\text { Cabra cor de laranja e galinha } \\
\text { vermelha. }\end{array}$ & S. Bárbara. \\
\hline Xangô & $\begin{array}{l}\text { Orixá do trovão, da justiça e } \\
\text { do fogo. }\end{array}$ & $\begin{array}{l}\text { Balança, machado(duplo) } \\
\text { elivro. }\end{array}$ & $\begin{array}{l}\text { Carneiro, galo e pombos } \\
\text { brancos. }\end{array}$ & $\begin{array}{l}\text { Jovem:São Miguel Arcanjo } \\
\text { Velho:São Jerônimo }\end{array}$ \\
\hline Obá & Sangue, ouvido, dona do lar. & $\begin{array}{l}\text { Navalha, roda de } \\
\text { madeira, timão, orelha. }\end{array}$ & $\begin{array}{l}\text { Galinha cinza, cabra marrom, } \\
\text { mocha e não coberta. }\end{array}$ & Santa Catarina \\
\hline Odé/Otim & Orixás da caça, fala, sono. & $\begin{array}{l}\text { Arco e flecha, cântaroe } \\
\text { bodoque. }\end{array}$ & Porco, galo carijó. & $\begin{array}{l}\text { Odé: São Sebastião } \\
\text { Otim: Santa Efigênia }\end{array}$ \\
\hline Ossanha & $\begin{array}{l}\text { Dono das folhas, protetor de } \\
\text { doenças internas, pernas, } \\
\text { ossos. }\end{array}$ & $\begin{array}{l}\text { Muleta, tesoura, agulha, } \\
\text { linha de coser. }\end{array}$ & Bode, galo arrepiado. & São José, Santo Onofre. \\
\hline Xapanã & $\begin{array}{l}\text { Protetor de doenças } \\
\text { epidêmicas (variola, lepra, } \\
\text { cólera). }\end{array}$ & $\begin{array}{l}\text { Vassoura, corrente de } \\
\text { aço. }\end{array}$ & $\begin{array}{l}\text { Bode com aspas de qualquer } \\
\text { cor menos preto, galo prateado. }\end{array}$ & $\begin{array}{l}\text { Jovem: São Lázaro } \\
\text { Velho: Cristo das Chagas }\end{array}$ \\
\hline Oxum & $\begin{array}{l}\text { Dono da água doce, ouro, } \\
\text { riqueza, amor, vida. }\end{array}$ & $\begin{array}{l}\text { Leque, espelho, dinheiro, } \\
\text { corrente dourada, pente. }\end{array}$ & Cabra, galinha amarela. & $\begin{array}{l}\text { N. S. da Conceição } \\
\text { N.S. Aparecida }\end{array}$ \\
\hline Iemanjá & $\begin{array}{l}\text { Dona dos mares, maternidade } \\
\text { e da fertilidade. }\end{array}$ & $\begin{array}{l}\text { Âncora, barco, remo, } \\
\text { anel, brincos, perfumes. }\end{array}$ & Ovelha, cabra e galinha branca. & N.S. dos Navegantes. \\
\hline Oxalá & $\begin{array}{l}\text { Pai de todos os Orixás, vida, } \\
\text { paz, visão. }\end{array}$ & $\begin{array}{l}\text { Bastão, poemba, olho de } \\
\text { vidro. }\end{array}$ & Cabra, galinha branca. & Cristo, Espírito Santo. \\
\hline
\end{tabular}

Fontes: Corrêa, 2006; Oro, 2008.

\section{Considerações finais}

O campo afrorreligioso se desenvolveu e se espraiou no Rio Grande do Sul, Porto Alegre e outras regiões nacionais e transnacionais de maneira particular e complexa, estando atualmente o Batuque e a Linha Cruzada basicamente restritos ao contexto da capital e de sua região metropolitana. Assim, certas contingências históricas e sociais pelas quais passaram esses locais no extremo sul do Brasil foram fundamentais para sua consolidação e circulação. Segundo Ari Pedro Oro,

o Batuque floresceu na segunda metade do século XIX e adaptou-se às condições de um Rio Grande do Sul 'tradicional', eminentemente agrário, pois naquela forma religiosa a tradição regia a estrutura ritual 
com os orixás formando uma grande família patriarcal. Os sacrifícios de animais não ofereciam problemas num Estado pastoril e em uma Porto Alegre onde havia ainda bairros 'rurais'. As iniciações podiam ser longas, pois as relações de trabalho eram ainda relativamente frouxas. Já a Umbanda se instalou no RS na década de 1930 num quadro social em que a implantação do capitalismo encontrava-se numa fase mais adiantada: a economia se monetarizava, iniciava-se o processo de industrialização, já ocorria o êxodo rural. O tempo tomava nova dimensão. As pessoas centravam suas vidas em torno do trabalho. A Umbanda se adequou aos novos tempos: seus rituais não se prolongavam noite adentro, não faziam uso de tambores e não realizavam sacrifícios de animais. Dessa forma, os fiéis podiam cumprir suas obrigações religiosas sem alterar o ritmo do cotidiano; não se prejudicava o sono dos vizinhos e se levava em conta a diminuição dos espaços para criar os animais que, além disso, se tornavam uma mercadoria cara. A Linha cruzada surgiu a partir da década de 1960, numa fase de consolidação do capitalismo com o consequente incremento de graves problemas, tais como desemprego, insegurança, doenças, frustrações. Neste contexto, a Linha cruzada torna-se uma religião prática, pragmática, de serviço, que se especializa nas soluções sobrenaturais daqueles problemas (Oro, 2002: 358-9).

No esteio desse universo múltiplo e complexo, a historicidade do Batuque no Rio Grande do Sul, Porto Alegre e região metropolitana, acompanha a experiência da vida social, a segregação racial e espacial e a sua convivência com uma realidade "embranquecida" e que tende a invisibilizar o componente afro-orientado de sua cultura e identidade. De certa forma, pode-se afirmar que, no histórico contexto de luta por reconhecimento e afirmação, ou ao menos pela mera existência, a ancestralidade africana é reinterpretada continuadamente tanto pelos praticantes das religiões afrobrasileiras quanto por aqueles que se apropriam delas na construção de identidades religiosas, étnicas e políticas (Morais, 2012).

Assim, se a história do Batuque e de outras religiões de matriz africana atravessam a questão da negritude, atualmente este quadro se ampliou, dentro dos auspícios da modernidade que clamam por sociedades assim entendidas - "modernas" que reconheçam a sua pluralidade e que tratem a ela de forma mais inclusiva e simétrica. Portanto, o reconhecimento e o registro da história dessas populações consistem em um mínimo alento dentro do abismo da indiferença a que estão geralmente submetidas. 


\section{Referenciais}

ACOSTA, M. Contribuicion al estudo del Batuque. Una religión natural: ni locos, ni raros. Mimeo, Copyright Milton Acosta, Uruguai, 1996.

BEM, D. F. de. Tecendo o axé: uma abordagem antropológica da atual transnacionalização afro-religiosa nos países do Cone Sul. Porto Alegre: UFRGS, 2012, 220 p. Tese (Doutorado em Antropologia Social) - Programa de Pós-Graduação em Antropologia Social, Universidade Federal do Rio Grande do Sul, 2012.

BRAGA, R. G. Batuque Jêje-Ijexá em Porto Alegre: a música no culto aos Orixás. Porto Alegre: FUMPROARTE, Secretaria Municipal de Cultura de Porto Alegre, 1998.

CARVALHO, J. J. de. A força da nostalgia. A concepção de tempo histórico dos cultos afro-brasileiros tradicionais. In Religião e Sociedade, n. 14, p. 236-61, 1987.

CORRÊA, N. F. Panorama das religiões afro-brasileiras do Rio Grande do Sul. In: ORO, Ari (Org.) As religiões afro-brasileiras do Rio Grande do Sul. Porto Alegre: Editora da UFRGS, 1994, p. 9-44.

CORRÊA, N. F. O Batuque do Rio Grande do Sul: Antropologia de uma religião afrorio-grandense. São Luis: Cultura e Arte, 2006.

FRANCO, S. da C. Guia Histórico de Porto Alegre. Porto Alegre: Editora da Universidade/ UFRGS e Prefeitura Municipal de Porto Alegre, 1988.

FRANCO, S. da C. História Ilustrada de Porto Alegre. CEEE/RBS, 1991.

FRIGERIO, A. Umbanda e africanismo em Buenos Aires: duas etapas de um mesmo caminho religioso. In: Comunicações do ISER, Rio de Janeiro, n. 35, 1989, p. 52-63.

IBGE. Censo de 2010. www.ibge.gov.br. Consultado em 13 de Dez. 2014.

KERSTING, E. Negros e a modernidade urbana em Porto Alegre: A Colônia Africana (1890-1920). Dissertação de Mestrado em História, Programa de Pós-Graduação em História, UFRGS, 1998.

MORAIS, M. R. Políticas públicas e a fé afro-brasileira: uma reflexão sobre ações de um Estado laico. In: Ciencias Sociales y Religión/Ciências Sociais e Religião. Porto Alegre: 2012, ano 14, n. 16, p. 39-59.

OLIVEN, R. G. A parte e o todo: a diversidade cultural no Brasil-nação. Petrópolis: Vozes, 2006.

ORO, A. P. Axé Mercosul: as religiões afro-brasileiras nos países do Prata. Petrópolis: Vozes, 1999.

ORO, A. P. Religiões Afro-Brasileiras do Rio Grande do Sul: passado e presente. In: 
Estudos Afro-Asiáticos, Ano 24, nr. 2, 2002, p. 345-384.

ORO, A. P. O sacrifício de animais nas religiões afro-brasileiras: análise de uma polêmica recente no Rio Grande do Sul. In: Religião e Sociedade, v. 25, n. 2, Rio de Janeiro, ISER, p. 11-31, 2005.

ORO, A. P. As religiões afro-brasileiras do Rio Grande do Sul. Debates do Ner, Porto Alegre, Ano 9, N. 13, p. 9-23, jan-jun 2008.

PI HUGARTE, R. Transnacionalização da religião no Cone-Sul: o caso do Uruguai. In: ORO, A. P; STEIL, C. A. (Orgs.). Globalização e religião. Petrópolis: Vozes, 1997, p. 201-218.

PIERUCCI, A. F. Bye bye, Brasil: o declínio das religiões tradicionais no Censo 2000. Estudos Avançados, vol.18, n. 52, São Paulo, Set./Dec. 2004.

SILVA, M. H. N. da. O Príncipe Custódio e as religiões afro-gaúchas. Dissertação (Mestrado em Antropologia) - Programa de Pós-Graduação em Antropologia Social, Universidade Federal de Pernambuco, Recife, 1999.

TADVALD, M. Direito litúrgico, direito legal: a polêmica em torno do sacrifício ritual de animais nas religiões afro-gaúchas. In: Revista Caminhos, Goiânia, v. 5, n. 1, p. 129147, jan./jun. 2007.

TADVALD, M. Quando a intolerância religiosa atravessa as fronteiras nacionais: a guerra santa entre a Igreja Universal e as afro-religiões exportada do Brasil para a Argentina. In: Gestão e Desenvolvimento, ano XI, v. 11, n. 2, Agosto 2014, p. 93-104.

Recebido: $11 / 03 / 2016$

Received: 03/11/2016

Aprovado: 30/05/2016

Approved: 05/30/2016 